\title{
L'écriture désirante: Marguerite Duras, édition établie et présentée par Anne-Marie REBOUL et Esther
} SÁNCHEZ-PARDO

\section{Margareth Amatulli}

\section{(2) OpenEdition}

\section{Journals}

\section{Edizione digitale}

URL: https://journals.openedition.org/studifrancesi/12143

DOI: 10.4000/studifrancesi. 12143

ISSN: 2421-5856

\section{Editore}

Rosenberg \& Sellier

\section{Edizione cartacea}

Data di pubblicazione: 1 avril 2018

Paginazione: 169-170

ISSN: 0039-2944

Notizia bibliografica digitale

Margareth Amatulli, «L'écriture désirante: Marguerite Duras, édition établie et présentée par Anne-Marie REBOUL et Esther SÁNCHEZ-PARDo», Studi Francesi [Online], 184 (LXII | I) | 2018, online dal 03 juillet 2018, consultato il 18 novembre 2021. URL: http://journals.openedition.org/studifrancesi/12143 ; DOI: https://doi.org/10.4000/studifrancesi. 12143

Questo documento è stato generato automaticamente il 18 novembre 2021.

\section{(c) (i) (9)}

Studi Francesi è distribuita con Licenza Creative Commons Attribuzione - Non commerciale - Non opere derivate 4.0 Internazionale. 


\title{
L'écriture désirante: Marguerite Duras, édition établie et présentée par Anne-Marie REBOUL et Esther SÁNCHEZ-PARDO
}

\author{
Margareth Amatulli
}

\section{NOTIZIA}

L'écriture désirante: Marguerite Duras, édition établie et présentée par Anne-Marie REBOUL et Esther SÁNCHEZ-PARDO, Paris, L'Harmattan, 2016, «Espaces littéraires», 291 pp.

1 Le sei parti che compongono questo volume, corredate da due testi introduttivi firmati rispettivamente dalle due curatrici (Anne-Marie ReBoul DiAZ, L'écriture souveraine de Duras ou le texte porteur d'«un million d'images», pp. 15-33; Esther SÁNCHEZ-PARDO, Marguerite Duras et l'expérience des limites, pp. 35-42) e da un epilogo, testimoniano l'intensa riflessione critica condotta a Madrid durante un congresso internazionale dedicato a Marguerite Duras in occasione del primo centenario della nascita celebrato il 4 aprile 2014.

2 I quattro contributi che costituiscono la prima parte del volume, «Dans les arcanes du processus créatif: la dissolution des limites» insistono, secondo approcci diversi, sulla ridefinizione dei limiti nell'opera di una scrittrice che «questionne et redéfinit même les limites - les paradigmes - de la forme littéraire, dramatique et cinématographique, et même les catégories conceptuelles de la race et de l'ethnicité, de l'homosexualité et de l'hétérosexualité, de la fantaisie et la violence» (p. 40). Può trattarsi della dissoluzione di paradigmi autobiografici, come dimostrano Joëlle PAGÈs-PINDON leggendo nelle opere del «cycle atlantique» (cioè quelle direttamente ispirate da Yann Andréa nell'ultimo periodo di fertilità narrativa della scrittrice) la deriva della forma autobiografica verso una sorta di «automythographie», («écriture du mythe de soi») e 
«zoographie» («écriture du vivant») (Noir désir. Genèse de l'automythographie atlantique dans "Le livre dit", pp. 45-63) - e Antonella LiPscomB, rivisitando L'amant alla luce delle categorie della scrittura dell'io, tra biografia, autobiografia, autoritratto e finzione ("L'amant" de Marguerite Duras: entre réalité et fiction, pp. 65-75). Ma anche della dissoluzione dei limiti del soggetto e della storia a causa dell'alcool (Anne Lucile GÉRARDOT, L'alcool infini ou la dissolution des limites, pp. 77-85) o del disorientamento tra verità e finzione (Sabrina LusuRIELlo, "Le marin de Gibraltar": une histoire à la dérive, pp. 87-95) che necessariamente incide sulle scelte romanzesche di un testo autodistruttivo e malinconico come Le marin de Gibraltar.

3 La seconda parte del volume, «Le geste de l'écriture», si apre con una riflessione sul ruolo della musica nell'universo durassiano, a partire da una minuziosa lettura della versione radiofonica d'India Song registrata nell'aprile 1974, di cui Suk HEE Joo evidenzia la continuità armonica tra musica e voce alla luce delle analisi condotte da Vladimir Jankélévitch sulla temporalità della musica e i rapporti tra la scrittura e la performance (La musique et l'écriture durassienne: faire entendre l'inexprimable, pp. 99-114). I due saggi successivi insistono, rispettivamente, sulla retorica lacunare della Duras come riflesso di un'identità perduta (Anna LEDWINA, Le non-sens comme la marque de l'écriture expérimentale de Marguerite Duras, pp. 115-124) e sulla poeticità di Moderato cantabile ("Moderato cantabile" - récit poétique, pp. 125-131) che Letitia I LEA individua nell'apprensione dei personaggi, dello spazio e del tempo nonché nella tensione del romanzo verso il mito, confrontando l'opera alla teoria di Jean-Yves Tadié e agli elementi che per il critico concorrono alla definizione di un racconto poetico.

4 A cominciare da una riflessione sulla decostruzione del genere sessuale nel racconto per bambini Ah! Ernesto (Laurent CAMERINI, “Ah! Ernesto" de Marguerite Duras: «Vous voyez tout de suite le genre!», pp. 135-147), gli articoli della terza parte del volume, incentrati su "Le rejet de tous les stéréotypes», evidenziano il rifiuto della Duras verso ogni convenzione e distinzione di genere, così come verso la rappresentazione stereotipata del discorso amoroso. Per Rafael GUJARRO GARCíA (Les stratégies de représentation de la scène de passion dans les textes de Marguerite Duras, pp. 149-157) tale discorso rimane indicibile grazie alla presenza di personaggi dai contorni incerti e spesso intercambiabili e in virtù di «une substance sémantique fuyante et proscrite parce que non verbalisable» (p. 150). La trasgressione della tradizione letteraria relativa al primo amore, e contemporaneamente ai ruoli di genere, attraversa la lettura che Francisco José VIECO propone di L'amant (Le souvenir érotique de Marguerite Duras: entre l'attachement de l'amant et le détachement de l'aimée, pp. 159-169).

5 Le vice-consul e L'amante anglaise si prestano invece, nella quarta parte del volume, «Le savoir inné de Marguerite Duras: lectures psycanalitiques», a una lettura psicanalitica. Le teorie di Lacan supportano le riflessioni di Dominique CORPELET sull'impossibilità di dire del primo romanzo (La voix du réel dans l'écriture di "Vice-consul", pp. 173-186), mentre quelle di Barthes (per la questione del frammento), di Derrida (per la problematica della traccia) e di Kristeva (per la decapitazione) offrono a Sayan DAENGLONG (L'écriture criminelle et les trois témoins intrus: "L'amante anglaise" d'après Barthes, Derrida et Kristeva, pp. 187-203) gli strumenti teorici per ritornare sull'enigma della protagonista di L'amante anglaise la cui trasgressione «n'est d'ordre ni moral ni juridique, mais scriptural» (p. 188).

6 I contributi della successiva sezione, «Dans l'atelier d'une voix devenue oraculaire», vertono sulle opere della Duras più ai margini della critica. A partire da precisi 
frammenti (un piano fisso di Le camion, un articolo commissionatole da «Le matin» e un episodio autobiografico di Écrire), Olivier CHEVAL si sofferma sulla postura oracolare dell'autrice (La ruse de la pythie. Le rire de Marguerite devant la fin du monde, pp. 207-216). Katheryn TREMBLAY LAUZON indaga invece sull'engagement che emerge dalle cronache giornalistiche redatte da Duras, in risonanza con l'attualità socio-politica a lei contemporanea, per «France Observateur» tra il 1957 e il 1961 e presentate in Outside ("Outside" Inside Out: prémices à une étude de l'œuvre journalistique de Marguerite Duras, pp. 217-227). Il titolo dell'ultimo contributo di questa sezione, Comment le "groupe de la rue Saint- Benoît» a façonné la sensibilité politique de Marguerite Duras à l'altérité (pp. 229-238), manifesta chiaramente l'intento di Maya Michael che dimostra la forte ascendenza del gruppo che si ritrovava a casa dell'autrice, vero e proprio «lieu de solidarité et communauté expérimentale alternative» (p. 230), sulla rappresentazione di personaggi appartenenti a una comunità, e quindi moralmente obbligati ad assumersi una responsabilità personale e collettiva.

7 Gli studi su «L'impact de l'Amant à l'étranger», contenuti nell'ultima sezione della miscellanea, allargano la riflessione sulla ricezione dell'opera dell'autrice al di là dei confini francesi per mostrare, attraverso un'analisi contrastiva in termini traduttologici, lo «choc sexuel» (p. 248) tra la voce dell'autore e quella del traduttore presente nella versione ungherese del romanzo che Krisztina HoRvátH rileva nella presenza di alcuni lapsus traduttivi (Traduire Duras. Écriture féminine et traduction littéraire, pp. 241-249); o la perdita della musicalità dell'opera e la forte distanza tra la poetica dell'autore e quella del traduttore che Paola CADEDDU individua nella traduzione italiana (Transgression et traduction. La langue violée de Marguerite Duras et la version italienne de "L'amant", pp. 251-262). La fortunata accoglienza del romanzo in Cina ha aperto le porte anche fuori dall'Europa alla popolarità di una scrittrice che non cessa di influenzare le giovani generazioni orientali come dimostra Li ZHENG (Le ravissement de Duras. Critiques et études de l'écrivaine en Chine des années 80 à aujourd'hui, pp. 263-272). L'epilogo che chiude il volume contiene un'intervista, risalente al dicembre 1990, di Dominique de GASQUET a Carlos D'ALESSIO, autore della musica di alcune opere cinematografiche di Marguerite Duras, a partire da India Song che deve parte del proprio successo al compositore argentino. Una foto degli anni Settanta (p. 276) testimonia il fortunato sodalizio tra l'autrice e il musicista. 